\title{
A Comparison of Interpersonal Problem Solving and Life Satisfaction Level between Students with Single Parents and Two Parents*
}

\author{
Ahmet BEDEL $^{* *} \quad$ Erkan IȘIK ${ }^{* * *}$
}

Received: 08 July 2013

Accepted: 26 August 2014

\begin{abstract}
The purpose of this study was to examine the differences between single-parent and two-parent students' level of interpersonal problem solving and life satisfaction. With this purpose, 256 high school students (128 single-parent, 128 two parents) completed Interpersonal Problem Solving Inventory (Çam \& Tümkaya, 2008) and the Satisfaction With Life Scale (Diener, Emmons, Larsen, \& Griffin, 1985; Köker, 1991). Results revealed that students from single-parent families approached more negatively to interpersonal problems, used more insistentpersevering approach, and exhibited more constructive problem solving skills when compared with their counterparts. The results also indicated that students from two-parent families were more satisfied with their life. In the light of these findings, suggestions for preventive guidance interventions targeting students from single-parent families were emphasized and ideas for future research are discussed.
\end{abstract}

Keywords: interpersonal problem solving, life satisfaction, single-parent, two-parent, high school students

\section{Extended Abstract}

Purpose and Significance: As a part of social life, the individual interact with others from school and family within the network of social relationships. This interaction may cause several problems in some areas. Interpersonal problem, as defined by D'Zurilla, Nezu and Maydeu-Oliveras (2004), is the inability to solve a problem encountered and not to know how to solve that problem. The one who is aware of the interpersonal problem wants to get rid of the tension that is caused due to the interface between current situation and desired goal and tries several ways of solving the problem. Perceived gap between the current situation and the desired goal that includes efforts to eliminate the tension caused by the cognitive and behavioral process is called interpersonal problem-solving process (Öğ̈̈lmüş, 2001). Cognitive behavioral problem solving process is highlighted, and a variety of issues that have the potential for effective solutions to increase the possibility of choosing between alternatives is defined as a more effective solution (D'Zurilla \& Goldfried, 1971).

Single-parenthood brings many problems to those families (Epstein, 2001). The majority of these problems include financial inadequacy, social life, parenthood, child care, management of household and time (Boylu \& Öztop, 2013). An important example for this is the twice rate of dropouts exhibited by students from single-parent

\footnotetext{
"An earlier version of this research was presented at the XII ${ }^{\text {th }}$ National Congress of Psychological Counselling and Guidance.

*** Corresponding Author: Assist. Prof. Dr., Mevlana University, Konya, Turkey, abedel@ mevlana.edu.tr

**** Assoc. Prof. Dr., Mevlana University, Konya, Turkey, eisik@ mevlana.edu.tr
} 
families (Gladding, 2012). Another example is the high alcohol and cigarette abuse among the boys and suicide attempts among girls living in single-parent families (Asagem, 2011; Feyzioğlu \& Kuşçuoğlu, 2011). These kinds of inadequacies experienced in these families make them the focus of many researches. Previous research found that students from single-parent families demonstrate more aggression (Dizman \& Gürsoy, 2005), anger (Tambağ, 2004), depression (Barut, 1992) and less assertive and socially self-efficacious (Biçer, 2009), socially active (Balc1, 1999), securely attached to their care-givers (Şahin, 2009), and self-estimated (Uğurlu, 1994). The focus of the current research is to compare the interpersonal problem solving skills and overall life satisfaction levels of students from single-parent families and twoparent families. Therefore, the purpose of this study was to examine the differences between single-parent and two-parent students' level of interpersonal problem solving and life satisfaction in two samples of high school students.

Methods: The research was conducted in Konya with only high school students from single-parent and two-parent families. Interpersonal problem-solving skills were assessed using Çam and Tümkaya's (2008) "Interpersonal Problem-Solving Inventory" and the life satisfaction was assessed using a Turkish version of (Köker, 1991) Diener, Emmons, Larsen and Griffin's (1985) Satisfaction With Life Scale. Participants were a total of 256 high school students (128 students living in single-parent families and 128 students living in two-parent families).

Results: The results of the study indicated that students from single-parent families approached more negatively to interpersonal problems, used more insistent-persevering approach, and exhibited more constructive problem solving skills when compared with their counterparts. The results also indicated that students from two-parent families were more satisfied with their life.

Discussion and Conclusions: Positive orientation to social problem-solving model developed by D'Zurilla and Goldfried (1971) consists of a constructive problem-solving. Negative problem orientation, on the other hand, is away from the constructive problem solving, and it includes avoiding and impulsive style of problem solving. According to the model, as the negative problem orientation increases, people are expected to move away from constructive problem solving. Some of the contradictions of rapid changes in the adolescent's thoughts and feelings can be revealed. In addition to the pleasure of loneliness, longing to join a group, orientation to the future with enthusiasm, tendency of hopeful future orientation compared to desperateness are central contradicting emotions of this universe. Adaptation at any age brings emotional tension. Because adaptation to new situations requires a change in behaviors related to both mentality and actions (Yavuzer, 2000). In one hand, adolescents from single-parent families approach negatively to the problems they encounter and their thought about the constructive problem solving might reflect their discrepancy during this period. On the other hand, 
no significant associations were seen between negative approach and constructive problem-solving subscales of Interpersonal Problem Solving Inventory (Çam \& Tümkaya, 2008). Another finding was the Insistent-persevering approach of singleparent students was found to be higher than two-parent students. This result is consistent with constructive problem-solving attitudes. The correlation coefficient between two approaches is .63. One of the most important aspects of constructive problem solving process is insistent-persevering. The average score of life satisfaction was significantly lower in single-parent students. One possible explanation for this result may be the negative effects single-parent families experience during their efforts of adaptation to negative life events. 


\title{
Tek Ebeveyni Olan ve İki Ebeveyni Olan Öğrencilerin Kişiler Arası Problem Çözme ve Yaşam Doyumu Düzeylerinin Karşılaştırılması*
}

\author{
Ahmet BEDEL $^{* *} \quad$ Erkan IŞIK ${ }^{* * *}$
}

Makale Gönderme Tarihi: 08 Temmuz 2013 Makale Kabul Tarihi: 26 Ağustos 2014

ÖZET: Bu çalışmanın amacı tek ebeveyni olan ve iki ebeveyni olan öğrencilerin kişilerarası problem çözme ve yaşam doyumu düzeylerinin karşılaştırılmasıdır. Bu amaçla, 256 lise öğrencisine (128 tek ebeveynli ve 128 iki ebeveynli) Kişilerarası Problem Çözme Envanteri (Çam \& Tümkaya, 2008) ve Yaşam Doyumu Ölçeği (Diener, Emmons, Larsen \& Griffin, 1985; Köker, 1991) uygulanmıştır. Çalışmanın sonuçlarına göre, tek ebeveynli öğrenciler iki ebeveynli öğrencilerle karşılaştırıldığında, problemlere daha olumsuz ancak ısrarcı ve sebatkar yaklaşmakta ve daha yapıcı problem çözme becerileri kullanmaktadırlar. Ayrıca iki ebeveynli öğrencilerin genel yaşam doyum düzeylerinin tek ebeveynli öğrencilerden anlamlı düzeyde yüksek olduğu bulunmuştur. Bu sonuçlar doğrultusunda özellikle tek ebeveynli öğrencileri hedefleyen önleyici rehberlik programlarına yönelik öneriler getirilmiş ve bundan sonra bu konuda yürütülecek çalışmalar için de önerilerde bulunulmuştur.

Anahtar sözcükler: kişilerarası problem çözme, yaşam doyumu, tek ebeveyn, iki ebeveyn, lise öğrencileri

\section{Giriş}

Tek ebeveynli aile, eşlerden bir diğerinin ölüm, boşanma ya da ayrılma gibi sebeplerden dolayı kaybı sonucu ebeveyn olarak annenin ya da babanın tek başına ailedeki işlerin yönetiminden sorumlu olduğu aile tipidir (Musick \& Bumpass, 1999). $\mathrm{Bu}$ aileler iki ebeveynli ailelerle karşılaştırıldığında birçok yönden sorunlar yaşamaktadırlar (Epstein, 2001). Bu sorunlar arasında ekonomik yetersizlik, sosyal yaşam, ebeveynlik, çocuk bakımı, evle ilgili faaliyetlerin yürütülmesi ve zaman kullanımı öne çıkmaktadır (Boylu \& Öztop, 2013). Kendi kültürümüzde Aile ve Sosyal Araştırmalar Genel Müdürlüğü tarafindan yapılan geniş kapsamlı araştırmada anneler tek ebeveyn oldukları ilk zamanlarda genel olarak çocuğu tek başına yetiştirmekle ilgili yoğun bir endişe yaşadıklarını ifade etmişlerdir. Annelerin endişelerinin diğer önemli nedenleri ise tek ebeveyn olarak karşılaştıkları maddi sıkıntılar ve sosyal hayatta karşılaşıtkları sorunlardır. Aynı zamanda çocuklarda tek ebeveynli oldukları ilk dönemlerde, evden ayrilan ebeveyni bir daha görememe korkusu ya da vefat eden ebeveyne karşı duyulan özlem nedeniyle büyük bir üzüntü, mutsuzluk ve yalnızlık içinde olduklarını belirtmişlerdir. Özellikle 12 yaş ve üzerindeki çocuklar, çevresindekilere ya da yakınlarına karşı eskisine göre daha hırçın ya da öfkeli olduklarını dile getirmişlerdir. Tek ebeveynli olduktan sonra 12 yaş ve üzeri çocuklar ebeveynlerinin kendilerine duydukları sevginin azalacağını düşünürken; daha küçük yaştaki çocuklar ise anne babasının neden ayrıldığını anlamaya çalışmaktadır. Eğer çocuk tek ebeveynli olduğu ilk zamanı hatırlayamayacak kadar küçükse, bu tür sorgulamaları daha çok okula başladıktan sonra yapmaktadır. Bu süreci daha olumsuz

\footnotetext{
* Bu makalenin önceki bir versiyonu XII. Ulusal Psikolojik Danışma ve Rehberlik Kongresi’nde sözlü bildiri olarak sunulmuştur.

${ }^{* *}$ Sorumlu Yazar: Yrd. Doç. Dr., Mevlana Üniversitesi, Konya, abedel@ mevlana.edu.tr

**** Doç. Dr., Mevlana Üniversitesi, Konya, eisik@ mevlana.edu.tr
} 
tecrübe eden erkek çocuklarının içlerine çok daha fazla kapanık olduğu ve kendilerini daha zor ifade ettiği görülürken; kız çocukların öfkelerini daha rahat ifade ettiği ya da ölme isteğinden daha sık söz ettiği görülmüştür (Asagem, 2011).

Tek ebeveynli olmanın çocukların sosyal hayatına etkileri de genel olarak olumsuzdur. Özellikle ev dışı sosyal hayata daha çok karıştıkları ilkokul döneminde, tek ebeveynli olma sürecinde psikolojik destek almayan ya da anne ve babanın boşanma ya da vefat sonrası düzgün iletişim kuramadığı çocukların kendilerini akranlarından farklı hissettiği görülmektedir. Bu çocuklar tek ebeveynli olmayı utanılacak bir durum olarak görmekte; bu nedenle de çevreleriyle kurduğu iletişimi kısıtlamaktadırlar. Tüm sosyoekonomik seviyedeki ailelerden gelen tek ebeveynli çocuklar, okul başarılarının genel olarak olumsuz etkilendiğini belirtmiştir. Tek ebeveyne sahip olan çocuklar iki ebeveyninin de bulunduğu ailelerde yetişen çocuklarla kıyaslandığında iki kat daha fazla okul terki eğilimindedirler (Gladding, 2012). Özellikle 15-17 yaş grubunun ve düşük SES grubundaki erkek çocuklarının alkol ve sigara kullandığı görülmektedir. Kız çocuklar ise yaşadıklarıyla baş edemediği için intihar etmek isteğinden ya da intihar teşebbüsünde bulunduğundan söz etmişlerdir. Çocuklar tek ebeveynli aile oldukları ilk dönemde daha çok içlerine kapanmakta; yüksek sesle müzik dinlemeyi, resim yapmayı ve tek başlarına kalmayı tercih etmektedirler. Psikolojik destek alan çocuk sayısı ise özellikle erkek çocukları için oldukça düşüktür (Asagem, 2011; Feyzioğlu \& Kuşçuoğlu, 2011).

Çeşitli nedenlerle (vefat, boşanma, ayrı yaşama) tek ebeveynli yaşayan aileler ve çocuklar araştırmacıların dikkatini çekmektedir. Tek ebeveynli ailelerle ve çocuklarla ilgili yapılan araştırmalarda çeşitli değişkenlerin etkisi incelenmiştir. Uygur, Türkcan ve Geyran (1994) tarafından yapılan araştırmada, Adli Psikiyatri Birimine adli organlarca başvurusu sağlanan, çocuk ve ergenlerden oluşan 65 olgunun incelenmesinde parçalanmış aile oranının yüksek olduğu sonucu elde edilmiştir. Ebeveynlerin yaşadığı sıkıntılar çocuklarıyla kurduğu iletişimi de olumsuz yönde etkileyebilmektedir. Tek ebeveyn ve üvey ebeveynlerde bedensel ceza kullanımının daha sık olduğu bildirilmiştir (Bolton \& MacEachron, 1990; Akt: Bilgin, 2008). Anne-babası boşanmış çocukların kaygı düzeyinin, anne-babası boşanmamış olan çocukların kaygı düzeylerine göre daha yüksek olduğu, ayrıca benlik saygı düzeylerinin daha düşük olduğu sonucu elde edilmiştir (Bulut-Serin \& Öztürk, 2007; Öztürk, 2006). Ailelerinde tek ebeveyn olan anne olan ailelerdeki geçimsizlik düzeylerinin, anne-baba-çocuklardan oluşan ailelerin geçimsizlik düzeylerden anlamlı derecede yüksek olduğu belirlenmiştir (Şanlı \& Öztürk, 2012). Parçalanmış ailelerde, sıkıntı, uyku bozukluğu, adli başvuru, davranış sorunları, okul başarısızlığı, danışma amaçlı başvurma, aşırı hareketlilik, zarar verici davranışlar anlamlı olarak daha fazla bulunmuştur (Fidan, 2011). Evli olan ebeveynlerin ergenleri izleme davranışlarının boşanmış ebeveynlere göre daha fazla olduğu sonucu elde edilmiştir (Aksoy, Kahraman \& Kılıç, 2008). Anne yoksunu olan çocukların saldırganlık düzeylerinin, anne yoksunu olmayan çocuklardan daha yüksek olduğu gözlenmiştir (Dizman \& Gürsoy, 2005). Aileleri ile birlikte yaşayan öğrencilerin problem çözme becerisine ilişkin algı düzeyleri, tek ebeveynle yaşayan öğrencilere göre 
daha yüksektir (Yılmaz \& Sipahioğlu, 2012). Tam aileye sahip 11. sınıfa devam eden ergenlerin atılganlık ve sosyal yetkinlik beklenti düzeyleri parçalanmış aileye sahip ergenlerden anlamlı düzeyde yüksek çıkmıştır (Biçer, 2009). Araştırmalarda ailesinin yanında ve yetiştirme yurdunda kalan öğrencilerin sosyal ve psikolojik faktörler açısından farklılıkları karşılaştırılmıştır. Balcı (1999) tarafından yapılan araştırmada yetiştirme yurdu ile ailesi yanında kalan öğrenciler, sosyal ilişki düzeyleri yönünden karşılaştırıldığında, ailesi yanında kalan öğrencilerin sosyal ilişki düzeylerinin daha yüksek olduğu sonucu elde edilmiştir. Tambağ (2004) tarafindan yapılan araştırmada yetiştirme yurdunda yaşayan ergenlerin dünyaya ve diğerlerine yönelik öfke puanı, ailesi ile birlikte yaşayanlardan daha yüksek bulunmuştur. Şahin (2009) tarafından yapılan araştırmada ailesi yanında yaşayan ergenlerin güvenli bağlanma stili düzeylerinin yetiştirme yurdunda yaşayan ergenlerden anlamlı düzeyde yüksek olduğu, korkulu bağlanma stilinde ise yetiştirme yurdunda yaşayan ergenlerin ailesi yanında yaşayan ergenlerden anlamlı düzeyde yüksek olduğu sonucu elde edilmiştir. Uğurlu (1994) tarafından yapılan araştırma sonucunda yetiştirme yurdunda kalan ergenlerin atılganlık ve öz saygı düzeylerinin ailelerinin yanında kalan ergenlerden düşük olduğu bulunmuştur. Yılgör (1993) yetiştirme yurdu gençlerinin ailelerinin yanında yaşayan gençlere göre bedensel gelişim, toplumsal gelişim, psikolojik gelişim, gelecek beklenti ve istekleri ile ilgili problemleri daha yoğun yaşadıkları sonucunu elde etmiştir. Barut (1992) tarafindan yapılan araştırmada yetiştirme yurdunda kalan kız öğrencilerin ailesi yanında kalan kız öğrencilere oranla depresyon düzeylerinin daha yüksek olduğu sonucu elde edilmiştir. Araştırma sonuçlarında, sağlıklı bir aile ortamının dışında büyüyen çocukların zihinsel, fiziksel, davranışsal ve sosyal-duygusal alanlarda gelişimleri açısından dezavantajlı durumda oldukları gözlenmektedir.

Tek ebeveynli olmanın çocukların sosyal hayatına etkilerinin genel olarak olumsuz olduğu görülmektedir. Sosyal yaşamın doğası gereği bu çocuklar okulunda, ailesinde, çevresinde başkalarıyla sosyal ilişkiler ağı içerisinde etkileşimde bulunur. Bu etkileşim içerisinde pek çok alanda sorunla karşılaşabilirler. Kişiler arası sorun çözme D'Zurilla, Nezu ve Maydeu-Oliveras (2004) tarafından "bireyin karşılaştığı bir sorunu çözememesi ve nasıl çözeceğini bilememesi” olarak tanımlanmıştır. Benzer bir tanımda Öğülmüş (2001) kişiler arası sorun çözmeyi "mevcut durumla erişilmek istenen amaç arasındaki boşluğun algılandığı ve bunun yol açtığ1 gerginliği ortadan kaldırmaya yönelik çabaları içeren bilişsel ve davranışsal süreç” olarak tanımlamıştır. Sorun çözmede vurgulanan bilişsel davranışsal süreç, sorunlar için potansiyel etkili çözümlerin bulunması ve çeşitli alternatifler arasında daha etkili çözümün seçilmesinin ihtimalini arttırma olarak tanımlanmaktadır (D’Zurilla \& Goldfried, 1971). Bu tanımlarda sosyal problem çözme bilinçli tasarım, mantıklı, güçlü ve bir amaca yöneliktir. Sorun çözme sürecinin amacı, pozitif sonuçları en yüksek düzeye çıkarmak ve negatif sonuçları en alt düzeye indirmektir. Böylece, sorunlu durumlarda daha iyi sonuç almak, duygusal sıkıntıyı azaltmak hedeflenmektedir (D’Zurilla vd., 2004; D’Zurilla \& Chang, 1995). Kişiler arası yaşanılan sorunları çözmek için D’Zurilla ve Goldfried (1971) tarafından geliştirilen sosyal problem çözme modeline göre, sorun çözme yaklaşımı probleme yönelim ve problem çözme beceri stillerinden oluşmaktadır. Kişiler arası sorunu 
çözmesinde ergenin sorun hakkındaki düşündükleri ve algılaması soruna karşı yönelimini etkilemektedir. Bu model içerisinde probleme yönelim, probleme pozitif yönelim ve probleme negatif yönelim olarak ayrılmaktadır. Sorun hakkında olumlu düşünce, probleme pozitif yönelimdir. Probleme pozitif yönelim, yapıcı problem çözmeden oluşmaktadır. Probleme pozitif yönelimin genel yapısında; kazanmak veya yarar sağlamak için probleme değer biçme, problemin çözülebileceğine inanma, bir kişinin problemi başarılı bir şekilde çözebileceğine inanma (problem çözme öz yeterliliği), başarılı problem çözmenin zaman ve çaba gerektirdiğine inanma, kaçınmak yerine problem çözmeyi üstlenmesi gerektiği yer almaktadır (D'Zurilla, Chang \& Sanna, 2003; Eskin, 2009, 2010). Buna karşın olumsuz düşünce, probleme negatif yönelim olarak adlandırılmaktadır. Probleme negatif yönelim fonksiyonel olmayan probleme yönelimdir. Probleme negatif yönelim şu genel eğilimleri içerir: Problemi, iyi oluşu etkileyen önemli bir tehdit olarak görme (psikolojik, sosyal, ekonomik), kişinin kendi kişisel yeteneğiyle problemi başarılı bir şekilde çözeceğine güvenmeme (düşük problem çözme öz yeterliliği) ve kolay düş kırıklığına uğrama (düşük hayal kırıklığ 1 toleransı) eğilimleri bulunmaktadır (D’Zurilla vd., 2004). Kişiler arası sorunlarda kendi davranışlarını düzenleyebilen bireyler yapıcı hareketler içerisinde gelişimsel avantaja sahip olabilmektedirler. Kişinin sorun çözme beceri yeteneğini kullanması yaşadığı güçlüklerle başa çıkabilme yeteneğini güçlendirmektedir. Aynı zamanda, akranları ile sağlıklı ilişki kurma ve bu ilişkiyi devam ettirme yeteneğini arttırmasına katkıda bulunmaktadir (Johnson, Johnson, Dudley, Mitchell \& Fredrickson, 1997; Johnson \& Johnson, 1994). Kişinin kendi yeteneklerine güvenmesinin, problemin çözülebilir olacağına inanmasının ve problemi çözmeye uğraşmasının (pozitif problem yönelimi) kişinin yaşam memnuniyetini ve kendisine olan öz saygısını arttırmada önemli bir faktör olduğu sonucu elde edilmiştir (Hamarta, 2009; Arslan, Hamarta \& Uslu, 2010).

Kişinin yaşam doyumunda, yaşamını devam ettirdiği aile ortamının önemi büyüktür (Lansford, Ceballo, Abbey \& Stewart, 2001). Çeşitli nedenlerden dolayı, bazı aileler tek ebeveynli olarak yaşamını devam ettirmektedir. Bir ergenin sosyal, ekonomik, fizyolojik ve psikolojik açıdan ihtiyaçlarını karşıladığı ve gelişimini sürdürdüğü en küçük toplumsal kurum ailedir. Ailede bireyler, bir etkileşim ağ içerisinde sorumluluklarını yerine getirerek yaşamlarını sürdürürler. Bu noktada aile yapısı, ergenin gelişim sürecini etkileyen önemli bir faktördür (Eryılmaz, 2010). Park'ın (2004) çalışmasına göre de, ergen öznel iyi oluşunu etkileyen dört önemli faktör bulunmaktadır. Bunlar destekleyici anne-babaya sahip olmak, zor işlerin üstesinden gelmek, olumlu yaşam olaylarını deneyimlemek ve önemli bireylerle gerçekleştirilen ilişkiden yüksek düzeyde doyum almaktır (Eryılmaz, 2010). Aile ortamında aile birliğini-beraberliğini hisseden ergenlerin, öznel iyi oluş düzeylerinin de anlamlı ve önemli düzeyde yükseldiği sonucuna varılmıştır (Eryılmaz, 2011). Besleyici ilişki tarzının öznel iyi oluşla pozitif yönde, zehirleyici ilişki tarzının ise negatif yönde ilişkili olduğunu ve her iki değişkenin de öznel iyi oluşu anlamlı düzeyde yordadığı bulunmuştur (Doğan \& Sapmaz, 2012). Yapılan çalışmalar, çocukların ruhsal gelişimi için en ideal ortamın anne-baba arasında çatışmanın olmadığı evlilikler olduğunu; bunun dışındaki tüm durumlarda (çatışmalı evlilik, çatışmasız veya çatışmalı boşanma) 
çocukların psikolojik açıdan örselendiğini ortaya koymuştur (Öngider, 2006). Tek ebeveynli ailelerin stres kaynaklarından biri de maddi güçlüklerin yaşanmasıydı. Araştırma sonuçlarına göre, finansal güçlükler arttıkça ailelerin yaşamdan duydukları tatmin azalmaktadır (Öztürk \& Boylu, 2013). Parçalanmış ve tam aileye sahip ergenlerin yaşam doyumu düzeyleri arasında anlamlı bir fark olduğu görülmüştür. Tam aileye sahip ergenlerin yaşam doyumu düzeyleri parçalanmış aileye sahip ergenlerin yaşam doyumu düzeylerinden daha yüksek olduğu bulunmuştur (Dingiltepe, 2009). Bu araştırmalar temelinde, sayıları her geçen gün artmakta olan (Kavas \& Gündüz-Hoşgör, 2013) tek ebeveynli ailelerde yaşamını sürdüren ergenlerin kişiler arası problem çözme becerilerinin ve yaşam doyumlarının incelenmesinin önemi ortaya çıkmaktadır.

\section{Araştırmanın Amacı}

$\mathrm{Bu}$ araştırmada amaç, tek ebeveyni ile veya iki ebeveyni ile birlikte yaşayan lise öğrencilerin kişiler arası problem çözme ve yaşam doyumu düzeylerinin karşılaştırılmasıdır.

\section{Yöntem}

$\mathrm{Bu}$ çalışma nicel araştırma yöntemlerinden genel tarama modeline uygun olarak yürütülmüştür.

\section{Araştırma Grubu}

Araştırmanın çalışma grubunu dokuz farklı devlet lisesinde öğrenim gören 128 tek ebeveynli ve 128 iki ebeveynli aileden gelen öğrenciler oluşturmaktadır. Öğrencilerin yaşları 14-19 arasında olup ortalaması 16.24'tür (Ss:1.5). Katılımcılara ait cinsiyet ve gelir düzeyi dağılımı tablo 1'de verilmiştir. Araştırmaya katılan iki öğrenci cinsiyetini belirtmemiştir.

Tablo 1

Araştırma Grubunun Cinsiyet ve Gelir Düzeyine Göre Dă̆ılımı

\begin{tabular}{lcccccc}
\hline & \multicolumn{2}{c}{ Tek Ebeveynli } & \multicolumn{2}{c}{ İki Ebeveynli } & \multicolumn{2}{c}{ Toplam } \\
\hline Aile Yapısı & $n$ & $\%$ & $n$ & $\%$ & $n$ & $\%$ \\
\hline Kız & 63 & 50.4 & 64 & 49.6 & 127 & 100 \\
Erkek & 64 & 49.6 & 63 & 50.4 & 127 & 100 \\
Gelir düzeyi & & & & & 101 & 100 \\
$0-1000$ & 39 & 38.6 & 62 & 61.4 & 102 & 100 \\
$1001-2000$ & 56 & 54.9 & 46 & 45.1 & 30 & 100 \\
$2001-3000$ & 17 & 56.7 & 13 & 43.3 & 7 & 100 \\
$3001-4000$ & 5 & 71.4 & 2 & 28.6 & 8 & 100 \\
4001 ve üzeri & 6 & 75 & 2 & 25 & & \\
\hline
\end{tabular}




\section{Veri Toplama Araçları}

Kişilerarası problem çözme envanteri. (KPÇE; Çam \& Tümkaya, 2008). KPÇE, problem çözme yaklaşım ve becerilerini ölçmek amacıyla geliştirilmiş 50 maddeden oluşan 5'li derecelendirmeli (1=Hiç uygun değil, 5=Tamamıyla uygun) Likert tipi bir ölçektir. Ölçek, Probleme Olumsuz Yaklaşma (POY), Yapıcı Problem Çözme (YPÇ), Kendine Güvensizlik (KG), Sorumluluk Almama (SA) ve Israrc1Sebatkar Yaklaşım (I-SY) olmak üzere toplam beş alt ölçekten oluşmaktadır. Her bir alt ölçek için elde edilen yüksek puan kişilerarası problem çözmeyle ilgili özelliğin yüksek olduğunu göstermektedir. KPÇE'nin alt ölçek puanlarının iç tutarlılık Cronbach Alfa katsayıları POY=.89, YPÇ=.87, KG=.67, SA=.68 ve I-SY=.70'dir. Envanterin testtekrar-test korelasyon değerlerinin ise .67 ile .84 arasında olduğu bulunmuştur (Çam ve Tümkaya, 2008).

Yaşam doyumu ölçeği. (YDÖ; Diener, Emmons, Larsen \& Griffin, 1985; Köker, 1991). YDÖ, öznel iyi oluşun bilişsel boyutu olan yaşam doyumunu ölçmek amacıyla geliştirilmiş beş maddeden oluşan 7'li derecelendirmeli ( $1=$ Hiç uygun değil, $7=$ Çok uygun) Likert tipi bir ölçektir. Ölçek puanları maddelere verilen puanların toplanmasıyla elde edilir ve yüksek puanlar bireyin yaşam doyumunun yüksekliğine işaret etmektedir. YDÖ Türkçe formu için iç tutarlılık Cronbach Alfa katsayı .76 olarak bulunmuştur. Ölçeğin test-tekrar-test korelasyon değerleri ise üç hafta ara ile yapılan ölçümlerde .85 olarak bulunmuştur.

\section{Verilerin Analizi}

Çalışmanın bağımlı değişkenleri olan kişilerarası problem çözme alt boyutları (POY, YPÇ, KG, SA ve ISY) ve yaşam doyumunun çalışmanın bağımsız değişkeni olan aile yapısına (tek-çift ebeveyn) göre anlamlı düzeylerde farklılaşıp farklılaşmadığını belirlemek amacıyla bağımsız değişkenler t testi kullanılmış ve analizler SPSS 15.0 programı ile gerçekleştirilmiştir.

\section{Bulgular}

Çalışmadan elde edilen verilerin analizine başlanmadan önce, veriler kayıp değerler ve çoklu analizlere uygunluk açısından değerlendirilmiş, çarpıklık ve basıklık değerleri sırasıyla -.61 ile .62 ve -.66 ile .42 arasında bulunmuş, verilerin normal dağılım varsayımını karşıladığı ve parametrik analizlere uygun olduğu gözlenmiştir.

Araştırmada kullanılan Kişilerarası Problem Çözme Envanteri alt ölçek ve Yaşam Doyumu Ölçeği puan ortalamaları, standart sapmaları ve bu puanlara ilişkin t-testi sonuçları tablo 2'de verilmiştir. 
Tablo 2

Tek Ebeveynli ve İki Ebeveynli Öğrencilerin Kişilerarası Problem Çözme Alt Ölçek ve Yaşam Doyumu Puanlarına İlişkin t testi sonuçları

\begin{tabular}{|c|c|c|c|c|c|c|c|}
\hline & \multicolumn{2}{|c|}{ Tek Ebeveynli } & \multicolumn{2}{|c|}{ İki Ebeveynli } & \multirow[b]{2}{*}{$t$} & \multirow[b]{2}{*}{$d f$} & \multirow[b]{2}{*}{$p$} \\
\hline & $\overline{\mathrm{x}}$ & ss & $\overline{\mathrm{x}}$ & ss & & & \\
\hline Probleme Olumsuz Yak. & 47.16 & 13.25 & 40.23 & 6.76 & -5.27 & 254 & $.000 * * *$ \\
\hline Yapıcı Problem Çözme & 56.14 & 10.74 & 52.89 & 10.34 & -2.47 & 254 & $.014^{*}$ \\
\hline Kendine Güvensizlik & 16.69 & 4.87 & 16.44 & 4.65 & -0.42 & 254 & .675 \\
\hline Sorumluluk Almama & 14.66 & 4.25 & 14.91 & 3.93 & 0.51 & 254 & .615 \\
\hline Israrc1-Sebatkâr Yak. & 22.85 & 4.05 & 21.58 & 4.66 & -2.33 & 254 & $.021^{*}$ \\
\hline Yaşam Doyumu & 20.77 & 6.89 & 23.31 & 6.64 & 3.01 & 254 & $.003 * *$ \\
\hline
\end{tabular}

$* \mathrm{p}<.05, * * p<.01, * * * p<.001$

Tablo 2 incelendiğinde, tek ebeveynli öğrencilerin probleme olumsuz yaklaşma, yapıcı problem çözme ve ısrarcı-sebatkâr yaklaşım puan ortalamaları iki ebeveynli öğrencilerin puan ortalamalarından anlamlı düzeyde yüksektir. Yaşam doyumu puan ortalamaları incelendiğinde ise, iki ebeveynli öğrencilerin puan ortalamaları tek ebeveynli öğrencilerden anlamlı düzeyde yüksektir.

\section{Tartışma}

Araştırma sonuçlarına göre, tek ebeveynli olan öğrencilerin kişiler arası sorunlara daha olumsuz yaklaştıkları gözlenmiştir. Probleme yönelme, bireyin kendi problem çözme becerisinin yanı sıra, onun genellikle yaşamdaki problemler hakkında ne düşündüğünü ve hissettiğini, duygusal ve bilişsel şemaları içermektedir (Arslan, Hamarta, Arslan \& Saygın, 2010; Arslan, 2005). Tek ebeveynli ailelerin ve çocukların özellikle ilk üç yılları en stresli zamanlarıdır (Gladding, 2012). Asagem (2011), tarafından yapılan araştırmaya göre, tek ebeveynli çocuklar evden ayrılan ebeveynini bir daha görememe korkusu, ya da vefat eden ebeveyne karşı duyulan özlem nedeniyle üzüntü, mutsuzluk ve yalnızlık içinde olduklarını ifade etmişlerdir. $\mathrm{Bu}$ yaşanılan olumsuz deneyim, tek ebeveynli ergenlerin kişiler arası problemlere karşı daha olumsuz yaklaşmalarında önemli olduğu düşünülmektedir. Özellikle 12 yaş ve üzerindeki çocuklar yakınlarına karşı eskisine göre daha hırçın ve öfkeli olduklarını yapılan görüşmelerde belirtmişlerdir. Tek ebeveynli olmak çocukların diğer alanlarını olduğu gibi, sosyal yaşamlarını da olumsuz yönde etkilemektedir. Bu çocuklar kendilerini farklı hissetmekte, tek ebeveynli olmayı utanılacak bir durum olarak görmektedirler. Bundan dolayı çevreleriyle kurdukları iletişim kısıtlanmaktadır, özellikle tek ebeveynli aile oldukları ilk dönemde daha çok içlerine kapanmaktadırlar (Asagem, 2011; Feyzioğlu \& Kuş̧̧uoğlu, 2011). Bu durum aynı zamanda okul yaşamını da olumsuz yönde etkileyebilmektedir. Düşük sosyoekonomik durumdaki erkek çocuklarda okulu 
tamamen bırakma ve çalışmaya başlama görülebilmektedir. Probleme olumsuz yaklaşma, yeni durumlarla baş edememe yaşça büyük erkek çocuklarda saldırganlık, alkol ve sigara gibi sorunların kendini göstermesine neden olabilmektedir. Kız çocukları ise, yaşadıklarıyla baş edemedikleri için intihar etmek istediğinden yada teşebbüsünde bulunduğundan söz etmektedir (Asagem, 2011). Yapılan araştırmalarda, tek ebeveynle yaşayan ailelerin ve çocukların sosyal, duygusal ve davranışsal gelişim alanlarında sıkıntılarla karşılaştığı görülmektedir. Yılmaz ve Sipahioğlu (2012) tarafından yapılan araştırmada tek ebeveynle yaşayan öğrencilerin problem çözme becerisine ilişkin alg1 düzeyi, aileleri ile birlikte yaşayan öğrencilerden anlamlı düzeyde düşüktür. $\mathrm{Bu}$ öğrencilerin, adli başvuru (Uygur vd., 1994), kayg1 düzeyi, benlik sayg1sı (Öztürk, 2006), saldırganlık düzeyi (Dizman \& Gürsoy, 2005) gibi değişkenlerde aileleriyle birlikte yaşayan ergenlere göre dezavantajlı oldukları görülmektedir. Benzer sonuçlar aileleri ile birlikte yaşayan ve yetiştirme yurtlarında yaşayan ergenlerin karşılaştırılmalarında da elde edilmektedir.

Bir diğer bulgu ise, tek ebeveynli olan öğrencilerin yapıcı problem becerilerinin daha yüksek olduğudur. Tek ebeveyni olan ergen bir taraftan yaşadığı probleme olumsuz yaklaşırken, bir taraftan da yapıcı problem çözmesi gerektiği ile ilgili düşüncesi bu dönemde yaşanan çelişkiyi yansıtabilir. Çünkü yapıcı problem çözme yeteneğini geliştirmesi, yaşadığı güçlüklerle başa çıkabilme yeteneğini güçlendirmesi anlamına gelmektedir. Tek ebeveynli ailedeki çocukların zorlukların yanında güçlü yönleri de bulunmaktadır. Çok erken yaşlarda sorumluluklar almakta, yaşamda bazı becerileri akranlarından önce öğrenmektedirler. Bu durum onlara yaşlarının ötesinde olgunluk kazandırmaktadır (Gladding, 2012). Yaşamın doğasında karşılaştıkları problemlerle baş başa kalması, onun problemlere olumsuz yaklaşmasına rağmen, problemini anlamaya ve çözmeye çalışmasında önemli bir faktör olduğu düşünülmektedir.

Tek ebeveynli olan öğrencilerin ısrarcı sebatkâr yaklaşım puan ortalamalarının daha yüksek olduğu sonucu elde edilmiştir. Bu sonuç öğrencilerin "yapıcı problem çözme" tutumları ile tutarlıdır. İki problem çözme yaklaşımı arasında $r=.63$ korelasyon vardır. Arslan ve diğerleri (2010) tarafından yapılan araştırmada, saldırganlık ile yapıcı problem çözme ve 1srarl1-sebatkâr yaklaşım arasında negatif yönde anlamlı bir ilişki olduğu, bununla birlikte yapıcı problem çözme ve 1srarl1-sebatkâr yaklaşımın, saldırganlığı anlamlı düzeyde açıkladığı bulunmuştur. Diğer bir ifadeyle saldırgan davranışın kişiler arası problem çözmenin olumsuz bir şekli olduğu düşünülürse, saldırgan davranış ve yapıcı problem çözme - problem çözmede ısrarcı sebatkâr tutum arasında negatif bir ilişki olması mantıklı görünmektedir. Çünkü yapıcı problem çözmenin en önemli unsurlarından biri problemin çözümü sürecinde sebatkâr olmadır.

Bir diğer bulguda ise, tek ebeveynli olan öğrencilerin iki ebeveynli olan öğrencilerden yaşam doyumlarının, anlamlı düzeyde düşük olduğu sonucu elde edilmiştir. Bu sonucun elde edilmesinde, tek ebeveynli olarak varlığını korumaya çalışması sürecinde, çocukların bu süreçten genellikle olumsuz biçimde etkilenmelerinin önemli bir faktör olduğu düşünülmektedir. Park’ın (2004) çalışmasına 
göre, destekleyici anne babaya sahip olmak ve olumlu yaşam olaylarını deneyimlemek, ergenin öznel iyi oluşunu etkileyen önemli faktörlerdir (Eryılmaz, 2010). Maalesef birçok çocuk böyle bir aile ortamından mahrumdur. Ergenin aile ortamında aile birlikteliğini hissetmesi onların yaşam doyumunu önemli düzeyde arttırmaktadır (Eryılmaz, 2011). Tek ebeveynli çocuklar aile birlikteliğini yaşayamamaktadırlar. Yapılan çalışmalar çocukların kendilerini iyi hissetmeleri ve ruhsal gelişimleri için en ideal ortamın anne baba arasında çatışmanın olmadığı evliliklerdir. Bunun dışındaki tüm durumların (çatışmalı evlilik, çatışmasız veya çatışmalı boşanma) çocukları psikolojik açıdan örselediğini ortaya konmuştur (Öngider, 2006). Ailenin parçalanmasından dolayı yaşadığı streste maddi kaynakların azalmasının önemli bir faktör olduğu bilinmektedir. Ailenin parçalanması beraberinde ekonominin de parçalanmasını getirmektedir. Anne ve babalar tek ebeveyn olarak ekonomik sıkıntı içinde bulunduklarını sıklıkla ifade etmişlerdir. Bu sıkıntılarını en çok çocuklarla ilgili konularla ilişkilendirmektedirler. Artan okul masraflarını karşılayamama, çocukları dershaneye gönderememe, beraber tatile çıkamama ve çocukların diğer isteklerini karşılayamamak, çocuk ile ilgili ekonomik sıkıntıların en çok hissedildiği konulardır (Asagem, 2011). Öztürk ve Boylu (2013) tarafından yapılan araştırmada finansal güçlükler arttıkça ailelerin yaşamdan duydukları tatmin azalmaktadır.

\section{Sonuç ve Öneriler}

Araştırma sonuçları genel olarak değerlendirildiğinde, tek ebeveynli olan ergenlerin iki ebeveynli olan ergenlere göre probleme olumsuz yaklaşma düzeylerinin yüksek ve yaşam doyumu düzeylerinin anlamlı derecede düşük olduğu görülmektedir. Bunun yanında, Kişilerarası Problem Çözme Envanterinin kendine güvensizlik ve sorumluluk almama alt boyutlarında tek ebeveynli ve iki ebeveynli öğrenciler arasında farklılığa rastlamamıştır. Araştırma sonucuna göre, tek ebeveynli ergenlerin probleme olumsuz yaklaşma düşüncelerinin azaltılmasının, olumlu kişilerarası problem çözme yaklaşımlarının kazandırılmasının önemi ortaya çıkmaktadır. $\mathrm{Bu}$ nedenle özellikle okullarda yapılacak önleyici rehberlik ve psikolojik danışma hizmetlerinde tek ebeveynli öğrencilerin tespit edilip daha olumlu kişilerarası problem çözme yaklaşım becerileri kazanmasına yardımcı olacak ve etkinlik ve çalışmalar yapılması uygun olacaktır. $\mathrm{Bu}$ öğrencilerin ve ailelerinin arkadaşları ve öğretmenlerinden aldıkları psikolojik ve sosyal desteklerin, ailelerin yaşadıkları çeşitli sıkıntıları azaltma konusunda önemli destek olacağ1 düşünülmektedir. Bundan sonra yürütülecek çalışmalarda tek ebeveyni olan öğrencilerin yaşıyor olabileceği kaygı, depresyon, akademik güdülenme gibi farklı psikolojik konularda iki ebeveyni olan öğrencilerle olan benzerlik ve farklılıkları incelenebilir. 


\section{Kaynakça}

Aksoy, A. B., Kahraman, Ö. G., \& K1lıç, Ş. (2000). Ergenlerin algıladıkları ebeveyn izleme ve destek davranışları. Inönü Üniversitesi Eğitim Fakültesi Dergisi, 9, 1-14.

Arslan, C. (2005). Kişiler arası çatışma çözme ve problem çözme yaklaşımlarının yükleme karmaşıklığı açısından incelenmesi. Selçuk Üniversitesi Sosyal Bilimler Enstitüsü Dergisi, 14, 75-93.

Arslan, C., Hamarta, E., Arslan, E., \& Saygın, Y. (2010). Ergenlerde saldırganlık ve kişiler arası problem çözmenin incelenmesi. İlköğretim Online, 9, 379-388.

Arslan, C., Hamarta, E., \& Uslu, M. (2010). The relationship between conflict communication, self-esteem and life satisfaction in university students. Educational Research and Reviews, 5, 31-34.

Asagem (2011). Tek Ebeveynli Aileler. Ankara: T.C. Başbakanlık Aile Ve Sosyal Araştırmalar Genel Müdürlügü Yayınları.

Balcı, T. (1999). Yetiştirme yurdu ile ailesi yanında kalan öğrencilerin kişisel ve sosyal uyum düzeylerinin okul başarılarına etkisi (Yayımlanmamış yüksek lisans tezi). Ondokuz Mayıs Üniversitesi, Samsun.

Barut, Y. (1992). Parçalanmış ailelerden gelen 15-18 yaş grubu yetiştirme yurdu çocuklarıyla normal aile çocuklarında görülen anksiyete ve depresyon sıklı̆̆ının incelenmesi (Yayımlanmamış doktora tezi). Hacettepe Üniversitesi, Ankara.

Biçer, E. (2009). Parçalanmış ve tam aileye sahip ergenlerin atılganlık ve sosyal yetkinlik beklenti düzeylerinin bazı demografik değişkenler açısından incelenmesi (Yayımlanmamış yüksek lisans tezi). Çukurova Üniversitesi, Adana.

Bilgin, A. (2008). Aile içi bedensel cezaya ilişkin bir çalışma. Ankara Üniversitesi Eğitim Bilimleri Fakültesi Dergisi, 41, 29-50.

Boylu, A. A. \& Öztop, H. (2013). Tek ebeveynli aileler: sorunlar ve çözüm önerileri, Sosyo Ekonomi Dergisi, 1, 208-220.

Bulut-Serin, N., \& Öztürk (2008). Anne-babası boşanmış 9-13 yaşlarındaki çocuklar ile aynı yaş grubundaki anne-babası boşanmamış çocukların benlik saygısı ve kaygı düzeyleri. Ahi Evran Üniversitesi Kırşehir Eğitim Fakültesi Dergisi (KEFAD), 8, $117-128$.

Çam, S., \& Tümkaya, S. (2008). Kişilerarası problem çözme envanteri lise öğrencileri formu'nun geçerlik ve güvenirlik çalışması. Uluslararası İnsan Bilimleri Dergisi, 5, $1-17$.

Diener, E., Emmons, R. A., Larsen, R. J., \& Griffin, S. (1985). The satisfaction with Life Scale. Journal of Personality Assessment, 49, 71-75. 
Dingiltepe, T. (2009). Parçalanmış ve tam aileye sahip ergenlerin yaşam doyumu düzeyleri ile yaşam kalite düzeylerinin karşılaştırılması (Yayımlanmamış yüksek lisans tezi). Çukurova Üniversitesi, Adana.

Dizman, H., \& Gürsoy, F (2005). İlköğretim dördüncü ve beşinci sınıfa devam eden anne yoksunu olan ve olmayan çocukların saldırganlık eğilimleri. Kastamonu Eğitim Dergisi, 13, 437-446.

Doğan, T., \& Sapmaz, F. (2012). Kişilerarası ilişki tarzları ve öznel iyi oluş. Türk Eğitim Bilimleri Dergisi, 10, 585-601.

D'Zurilla T. J., \& Chang, E. C. (1995). The relations between social problem solving and coping. Cognitive Therapy and Research, 19, 547-562.

D’Zurilla, T., Chang, E. C., \& Sanna, L. J. (2003). Self-esteem and social problem solving as predictors of aggression in college students. Journal of Social and Clinical Psychology, 22, 424-440.

D'Zurilla, T. J., \& Goldfried, M. R. (1971). Problem solving and behavior modification. Journal of Abnormal Psychology, 78, 107-126.

D’Zurilla, T. J., Nezu, A. M., \& Maydeu-Olivares, A. (2004). Social problem solving: Theory and assessment. In E. C. Chang, T. J. D'Zurilla, \& L. J. Sanna (Eds.), Social problem solving: Theory, research and training. Washington, DC: American Psychological Association.

Epstein, J. L. (2001). School, family, and community partnerships: Preparing educators and improving schools. Boulder, CO: Westview Press.

Eryılmaz, A. (2010). Aile yapısı ergeni mutlu eder mi? Aile ve Toplum Dergisi, 6, 2130.

Eryılmaz, A. (2011). Ergenlerin öznel iyi oluşlarıyla aile ortamları arasındaki ilişki. Aile ve Toplum Dergisi, 7, 93-101.

Eskin, M. (2009). Sorun çözme terapisi. Ankara: HYB Basım Yayın.

Eskin, M. (2010). Sorunlarımı çözebilirim. Ankara: Hekimler Yayın Birliği.

Feyzioğlu, S., \& Kuşçuoğlu, C. (2011). Tek ebeveynli aileler. Aile ve Toplum Dergisi, 7, 97-109.

Fidan, Y. T. (2011). Bir çocuk-ergen ruh sağlığı ve hastalıkları polikliniğine başvuran çocuk ve ergenlerin ruhsal belirtileri ve risk faktörlerinin değerlendirilmesi. Konuralp Tip Dergisi, 3, 1-8.

Gladding, T. S (2012). Aile terapisi tarihi, kuram ve uygulamaları. (Çev. Edi: İbrahim Keklik ve İbrahim Yıldırım). Ankara: Türk Psikolojik Danışma ve Rehberlik Derneği Yayınları. 
Hamarta, E. (2009). A prediction of self-esteem and life satisfaction by social problem solving. Social Behavior and Personality, 37, 73-82.

Johnson D. W., \& Johnson R. T (1994). Constructive conflict in the schools. Journal of Social Issues, 50, 117-137.

Johnson, D. W., Johnson, R., Dudley, B., Mitchell, J., \& Fredrickson, J. (1997). The impact of conflict resolution training on middle school student. The Journal of Social Psychology, 137, 11-21.

Kavas, S., \& Gündüz-Hoşgör, A. (2013). The parenting practice of single mothers in Turkey: Challenges and strategies. Women's Studies International Forum, 40, 5667.

Köker, S. (1991). Normal ve sorunlu öğrencilerde yaşam doyumu düzeyinin karşılaştırılması (Yayımlanmamış yüksek lisans tezi). Hacettepe Üniversitesi, Ankara.

Lansford, J. E.,Ceballo, R., Abbey, A., \& Stewart, A. J. (2001).Does the family structure matter? A comparison of adoptive, two-parent biological, single-mother, stepfather, and stepmother households. Journal of Marriage and Family, 63, 840852.

Musick, K., \& Bumpass, L. (1999). Prior experiences in the family. In A. Booth, A. C. Crouter and M. J. Shanahan (Eds.), Transitions to adulthood in a changing economy. CT: Praeger Publishers.

Öğülmüş, S. (2001). Kişiler arası sorun çözme becerileri ve eğitimi. Ankara: Nobel Yayın Dağıtım.

Öngider, N. (2006). Evli ve boşanmış ailelerde algılanan ebeveyn kabul veya reddinin çocuğun psikolojik uyumu üzerindeki etkileri. (Yayımlanmamış doktora tezi). Ege Üniversitesi, İzmir.

Öztürk, M. S., \& Boylu, A. A. (2013). Tek ebeveynli ailelerin yaşadıkları finansal güçlüklerin yaşam tatminleri üzerindeki etkisinin incelenmesi, Hacettepe Üniversitesi Sosyolojik Araştırmalar E Dergisi, Retrieved from http://www.sdergi.hacettepe.edu.tr/

Öztürk, S. (2006). Anne-babası boşanmış 9-13 yaşlarındaki çocuklar ile aynı yaş grubundaki anne-babası boşanmamış çocukların benlik saygısı ve kaygı düzeyleri ilişkisi (Yayımlanmamış yüksek lisans tezi). Dokuz Eylül Üniversitesi, İzmir.

Park, N. (2004). The role of subjective well-being in positive youth development, The Annals of the American Academy of Political and Social Science, 591, 25-39.

Şahin, G. (2009). Yetiştirme yurdunda ve ailesinin yanında yaşayan ergenlerin bağlanma stilleri ile kimlik statüleri arasindaki ilişkinin incelenmesi (Yayımlanmamış yüksek lisans tezi). Selçuk Üniversitesi, Konya. 
Şanlı, D., \& Öztürk, C. (2012). Annelerin çocuk yetiştirme tutumlarını etkileyen etmenlerin incelenmesi. Buca Eğitim Fakültesi Dergisi, 32, 31-48.

Tambağ, H. (2004). Aileleri ile birlikte ve yetiştirme yurtlarında yaşayan adölesanların öfke ifade etme biçimleri (Yayımlanmamış yüksek lisans tezi). Hacettepe Üniversitesi, Ankara.

Uğurlu, U. (1994). Yetiştirme yurdunda yaşayan ergenler ile ailesiyle birlikte yaşayan ergenlerin özsaygı ve atılganlık düzeyleri açısından karşılaştırılması (Yayımlanmamış yüksek lisans tezi). Atatürk Üniversitesi, Erzurum.

Uygur, N., Türkcan, S., \& Geyran, P (1994). Adli psikiyatride çocuk ve ergen suçları. Düşünen Adam, 7, 20-24.

Yavuzer, H. (2000). Okul çă̆l çocuğu. İstanbul: Remzi Kitabevi.

Y1lgör, F. (1993). Yetiştirme yurdunda yaşayan 13-17 yaş grubu okuyan gençler ile aileleri yanında yaşayan ve okuyan aynı yaş grubu gençlerin ergenlik problemlerinin karşılaştırılması (Yayımlanmamış yüksek lisans tezi). Marmara Üniversitesi, İstanbul.

Yılmaz, H., \& Sipahioğlu, Ö. (2012). Faklı risk gruplarındaki ergenlerin psikolojik sağlamlıklarının incelenmesi. Illköğretim Online, 11, 927-944. 